\title{
Study of Low Voltage Prebreakdown Sites in Multicrystalline Si Based Cells by the LBIC, EL, and EDS Methods
}

\author{
V. I. Orlov, ${ }^{1,2}$ E. B. Yakimov, ${ }^{2}$ E. P. Magomedbekov, ${ }^{3}$ and A. B. Danilin ${ }^{4}$ \\ ${ }^{1}$ Institute of Solid State Physics RAS, Chernogolovka, Russia \\ ${ }^{2}$ Institute of Microelectronics Technology RAS, Chernogolovka, Russia \\ ${ }^{3}$ D. Mendeleev University of Chemical Technology of Russia, Moscow, Russia \\ ${ }^{4}$ Innotra LLC, Moscow, Russia \\ Correspondence should be addressed to E. P. Magomedbekov; eldar@rctu.ru
}

Received 16 February 2017; Revised 20 March 2017; Accepted 21 March 2017; Published 10 April 2017

Academic Editor: Sergei Sergeenkov

Copyright (c) 2017 V. I. Orlov et al. This is an open access article distributed under the Creative Commons Attribution License, which permits unrestricted use, distribution, and reproduction in any medium, provided the original work is properly cited.

\begin{abstract}
Breakdown sites in multicrystalline Si solar cells have been studied by reverse-bias electroluminescence, electron beam induced current (EBIC) and laser beam induced current (LBIC), and Energy Dispersive X-Ray Spectroscopy methods. In the breakdown sites revealed by EL at small reverse bias $(\sim 5 \mathrm{~V})$, the enhanced aluminum and oxygen concentration is revealed. Such breakdowns can be located inside the depletion region because they are not revealed by the EBIC or LBIC methods. Breakdowns revealed by EL at larger bias correlate well with extended defects in the EBIC and LBIC images.
\end{abstract}

\section{Introduction}

Solar cells made from Si regularly suffer from shunts, which are internal short circuits degrading the parameters of the cells and often even preventing their applicability (see [1-6] and the references therein). Therefore, it is very important to study their nature and to understand the mechanisms of their formation. In spite of numerous studies done by various authors, the cause and occurrence of shunts and electrical breakdown in solar cells are not fully understood yet [6]. The reason for this misunderstanding is determined by the manifold nature of shunts, especially in multicrystalline $\mathrm{Si}$, and by a variety of extended defects and impurities in this material. Among various types of shunts, those associated with local breakdown of solar cells under reverse bias can be mentioned [5-9]. It was shown that such breakdown sites can be revealed by reverse-bias electroluminescence (EL) [5-10] and their classification was carried out $[6,11]$. The correlation of EL images with those obtained by the electron beam induced current (EBIC) method sometimes allows finding a link between these sites and extended defects $[6,11]$. However, for some breakdown sites (usually revealed at low reverse bias), no correlation with extended defects was revealed $[6,7,11]$.
In the present study, the breakdown sites in multicrystalline $\mathrm{Si}$ based solar cells are revealed by the reverse-bias EL. The EL images obtained at different reverse-bias values are compared with those obtained by the EBIC and light beam induced current (LBIC) methods to correlate them with extended defects. The local composition at the breakdown sites was studied.

\section{Experimental}

Solar cells studied were formed on the multicrystalline Si wafers, $200 \mu \mathrm{m}$ thick and $150 \times 150 \mathrm{~mm}^{2}$ in size, cut from bricks grown by casting. The wafer surface was acidic textured. The emitter was produced by $\mathrm{POCl}_{3}$ diffusion. $\mathrm{SiN}_{x}$ layer was deposited by PECVD for passivation. Front Ag and rear $\mathrm{Al}$ contacts were screen-printed and fired. The samples for investigations with an area of a few $\mathrm{cm}^{2}$ were cut from the solar cells. Most parts of the grain boundaries in these samples, as obtained by Electron Backscatter Diffraction, are of $\Sigma 3$ and random types and the dislocation density varies in the range from $10^{5}$ to $10^{6} \mathrm{~cm}^{-2}$ [12].

The electroluminescence images were recorded using an optical microscope and a highly sensitive video camera 


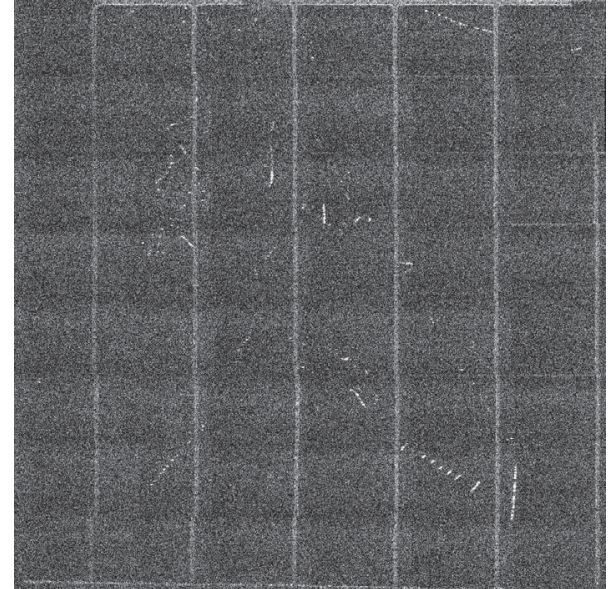

FIGURE 1: EL image of a large area fragment of structure under study obtained at $10 \mathrm{~V}$ reverse bias. The distance between contact strips is $2.3 \mathrm{~mm}$.

equipped with a silicon charge-coupled device array. The EBIC investigations were carried out with a scanning electron microscope (SEM) JSM 840A (JEOL) at room temperature with beam energy of $35 \mathrm{keV}$ and beam current of $10^{-10} \mathrm{~A}$. The LBIC measurements were carried out at room temperature with a $980 \mathrm{~nm}$ semiconductor laser as an excitation source. Solar cell breakdown is often associated with precipitates or surface contamination $[6,7,13]$; therefore, to study the nature and composition of these precipitates and contamination, the local composition in the breakdown sites was determined by Energy Dispersive X-Ray Spectroscopy (EDS) in the JSM 6490 (JEOL) with INCA 350 system (Oxford Instruments).

\section{Results and Discussions}

A large area EL image of solar cell obtained at reverse bias of $10 \mathrm{~V}$ is shown in Figure 1 (i.e., in the regime, in which the breakdown sites can be associated with decorated extended defects $[6,11])$. A lot of inhomogeneously distributed breakdown defects of different forms can be seen as bright points. It should be mentioned that large enough areas are free from breakdown defects. The images of a cell fragment containing breakdown defects were obtained at different reverse-bias values. Such images with higher magnification are shown in Figure 2. It is seen that at small bias only a few breakdown sites can be revealed as bright spots (shown with white arrows). Typical breakdown sites revealed at small bias (socalled type 1 breakdown $[6,11,14]$ ) are shown in Figures 2(b) and 2(c) as two bright spots with brightness increasing with reverse bias. In Figure 2(c) obtained at $19 \mathrm{~V}$ reverse bias, some additional bright points appear (line of bright points between two bright defects). An analysis of EBIC and LBIC images of the same region shows that the bright spots revealed at larger reverse voltage correlate well with some random grain boundaries (compare Figures 2(c) and $3)$. This is in good agreement with the previously observed results for breakdowns of type II $[6,11]$ that allows associating these breakdown sites with decorated grain boundaries. As seen in Figure 2(c), the EL images of such breakdowns are not continuous lines but instead consist, as in [11], of bright point sets. Moreover, not all electrically active grain boundaries introduce breakdown sites. It should be noted that, in the EBIC images of grain boundary producing the line breakdown sites (Figure 3(a)), some dark points and lines can be also seen. That is, precipitates decorating this grain boundary can be revealed in the EBIC mode. However, our EDS investigations do not reveal any compositional changes in such breakdown sites. Of course, it should be taken into account that the sensitivity of EDS method in the scanning electron microscope due to rather large excitation volume is rather low and this method cannot detect small precipitates. Thus, it can be stated that, in the cells studied, the precipitates formed on grain boundaries and other extended defects are the reason for type II breakdown in accordance with previous investigations $[6,11]$; however, the composition of these precipitates was not established. It only could be mentioned that direct evidence was previously obtained (see [6] and the references therein) that $\mathrm{FeSi}_{2}$ precipitates are responsible for type II breakdown and probably this is the case in the studied cells also. It should be also mentioned that most $\Sigma 3$ grain boundaries cannot be revealed in the EBIC or LBIC modes due to their low recombination activity [15]. An absence of line breakdown defects, which cannot be associated with the defects in EBIC and LBIC images, may indicate that $\Sigma 3$ grain boundaries do not cause breakdown. It should be also noted that while at such bias type III avalanche breakdown is usually observed [6], in the samples studied, probably type II breakdown regime is still realized because all additional breakdown sites can be associated with grain boundaries; however, this point was not studied in detail here.

Further, we will focus on the breakdown sites shown in Figure 2(b). A comparison of EL images with EBIC and LBIC images of the same region (Figure 3 ) does not reveal any electrically active extended defects in these sites that correlate with previous investigations $[6,11]$. Therefore, it could be assumed that the corresponding defects are located in the depletion region or in highly doped $\mathrm{n}^{+}$-layer, where they do not produce the EBIC or LBIC contrast. In the secondary electron image surface stains were observed at some breakdown sites (Figures 4 and 5) similar to those observed in [7] but at other sites no surface defects were revealed at the positions of type I breakdowns. EDS mapping reveals the enhanced aluminum and oxygen concentrations at these sites (Figures 4 and 6) that well correlate with the results obtained in $[2,7]$, where it was concluded that these breakdowns arise due to contamination of the wafer with aluminium particles before and during processing. It should be noted that, as shown in [16], Al spikes indeed can be formed and in n-Si they can produce short circuits in solar cells. Here, p-Si is used; therefore, Al exhibiting precipitate behavior can be different from that in [16]. Nevertheless, the results presented confirm the effect of Al containing precipitates on the low voltage solar cell breakdown in accordance with [7]. It should be also noted that $\mathrm{Al}$ contacts were made on the back surface while the $\mathrm{Al}$ precipitates are revealed on the front one. Al can come from $\mathrm{Ag}$ paste used for top contact formation, in which $\mathrm{Al}$ sometimes is added, although the breakdown sites studied are 


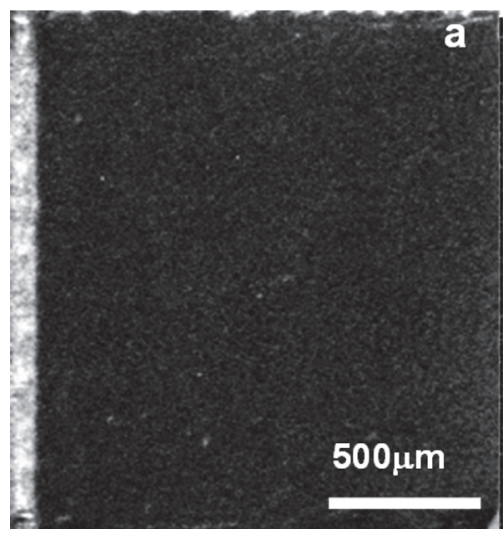

(a)

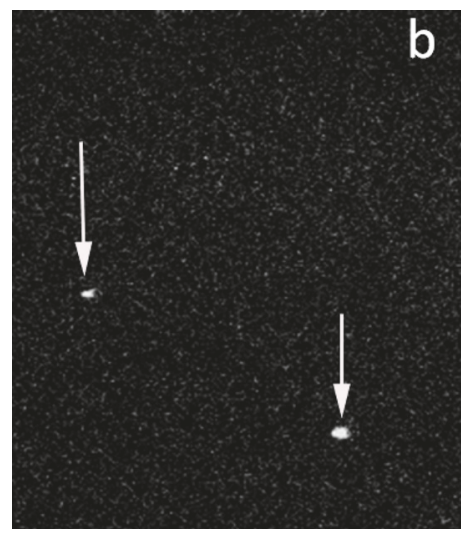

(b)

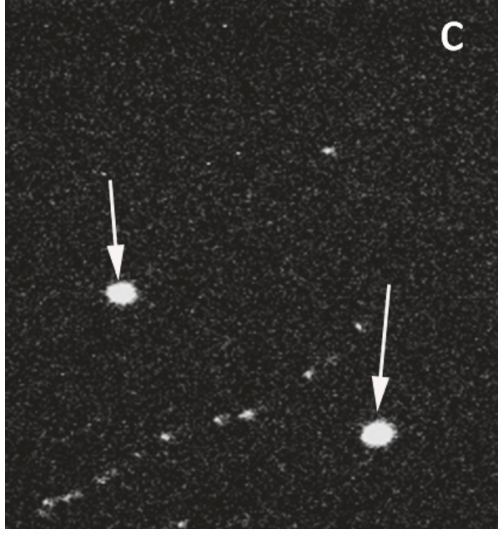

(c)

FIGURE 2: EL images of a solar cell fragment obtained at reverse bias $U_{b}=0 \mathrm{~V}$ (a), $5 \mathrm{~V}$ (b), and $19 \mathrm{~V}$ (c). Type I breakdown sites are shown with white arrows.

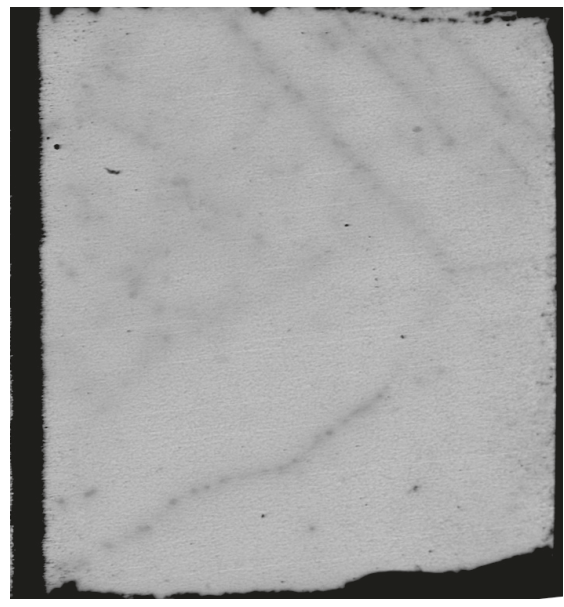

(a)

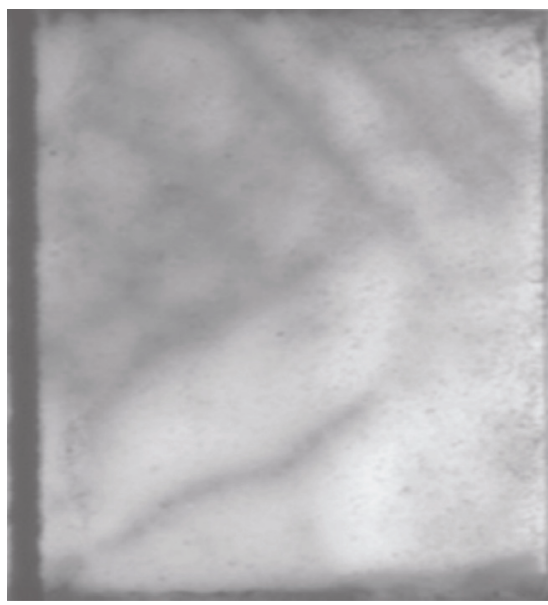

(b)

FIGURE 3: EBIC (a) and LBIC (b) images of the same region as in Figure 2.
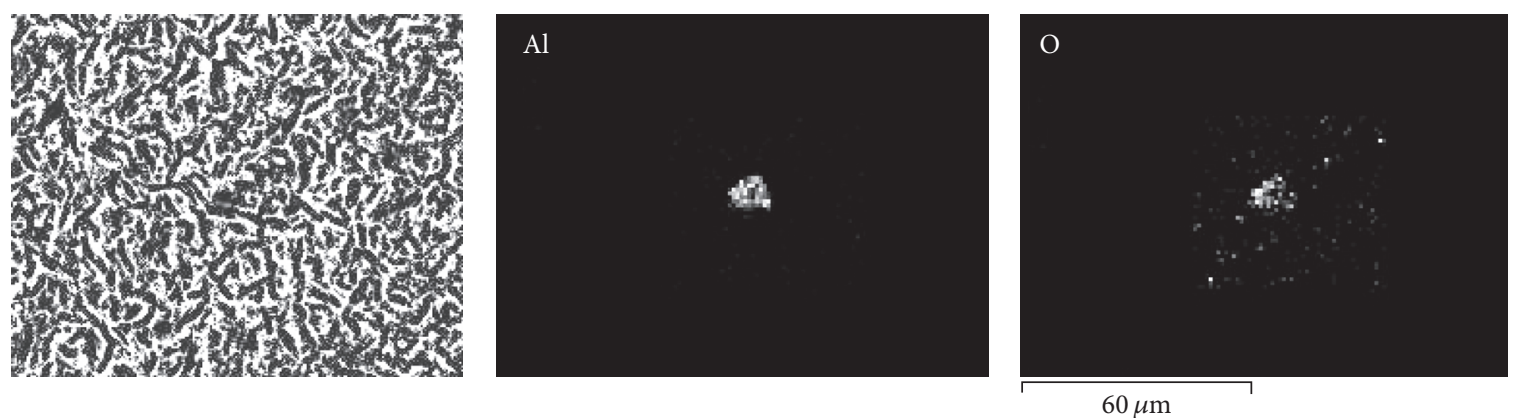

FIGURE 4: SE image and EDS maps of aluminum and oxygen distribution for the left breakdown site in Figure 2(b).

located far enough from the contact grid. (EL cannot reveal breakdown sites under contacts.) It should be mentioned that the composition of some breakdown sites (e.g., right one in Figure 2(b)) is more complex. Besides aluminum and a small amount of oxygen, the enhanced concentration of carbon and sodium is also revealed (Figure 6). As assumed in [17, 18], $\mathrm{SiC}$ filaments can be a reason for some shunts. Therefore, for these particular defects, an additional possible reason for breakdown could be considered (i.e., Al spikes may be also formed on the $\mathrm{SiC}$ filaments). 


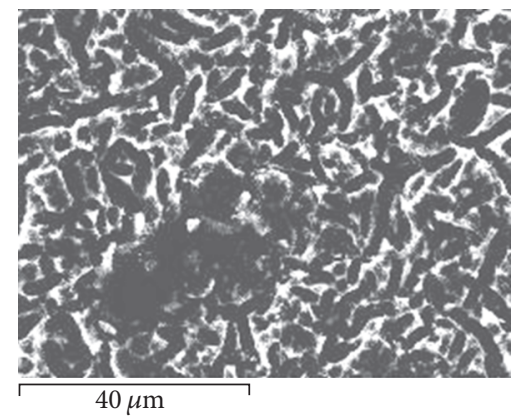

FIGURE 5: SE image of the right breakdown site in Figure 2(b).
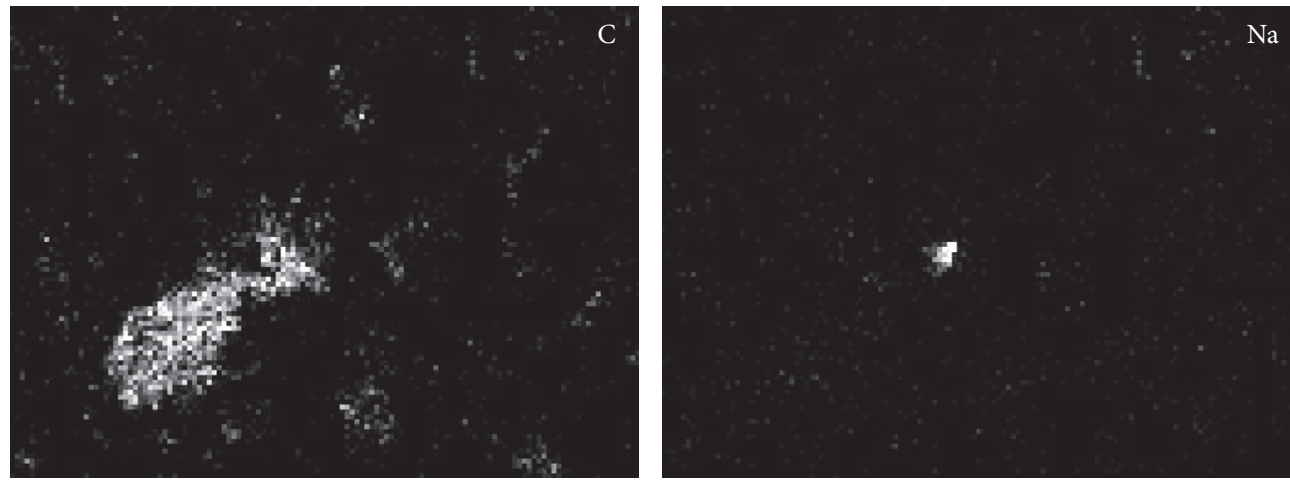

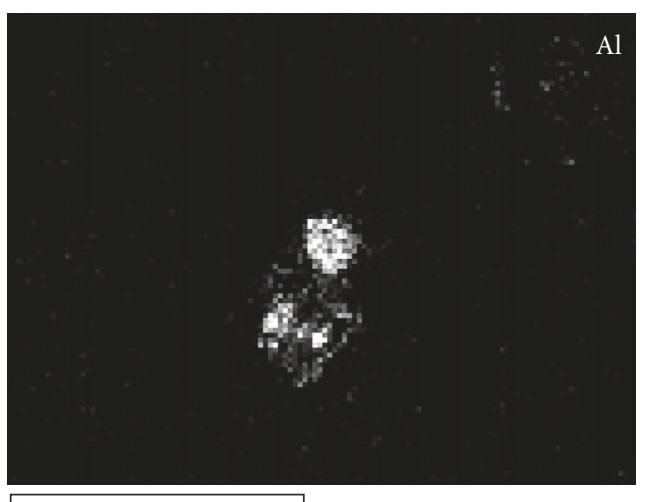

$40 \mu \mathrm{m}$

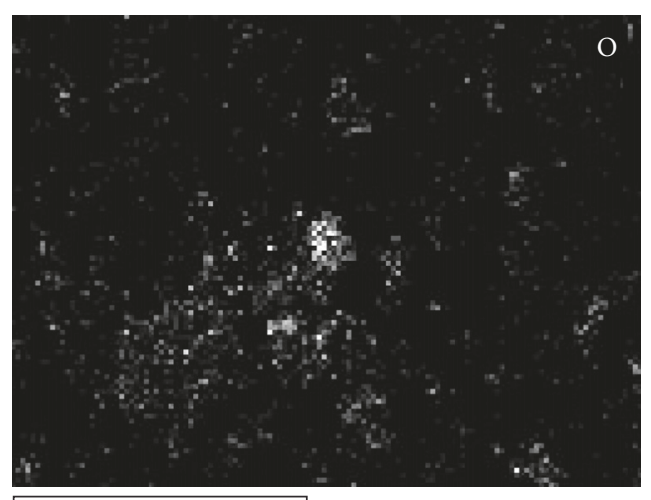

$40 \mu \mathrm{m}$

FIgURE 6: EDS maps for the right breakdown site in Figure 2(b).

In order to determine the spectral distribution of the luminescence arising from the type I breakdowns spectrally resolved EL measurements were performed at different reverse voltages for a few of them. Typical EL spectra obtained from the breakdowns of type I are presented in Figure 7. It is seen that the spectra are practically independent of the applied reverse bias. They exhibit a broad band ranging from $400 \mathrm{~nm}$ beyond $750 \mathrm{~nm}$. These spectra are similar to those observed in [7]; however, they have a maximum at about $570 \mathrm{~nm}$; that is, they are blue-shifted according to $715 \mathrm{~nm}$ observed in [7].

\section{Conclusion}

Breakdown sites in multicrystalline Si solar cells have been studied by reverse-bias EL, EBIC, LBIC, and EDS methods.
It is shown that the breakdown sites revealed by EL at small reverse bias in breakdown regime 1 can be associated with Al spikes located inside the depletion region. Breakdowns revealed by EL at larger bias in accordance with previous investigations correlate well with extended defects in the EBIC and LBIC images and can be associated with small precipitates formed on the random grain boundaries.

\section{Conflicts of Interest}

The authors declare that they have no conflicts of interest

\section{Acknowledgments}

The authors would like to thank Professor X. Yu for providing the samples used in this study. The work of 


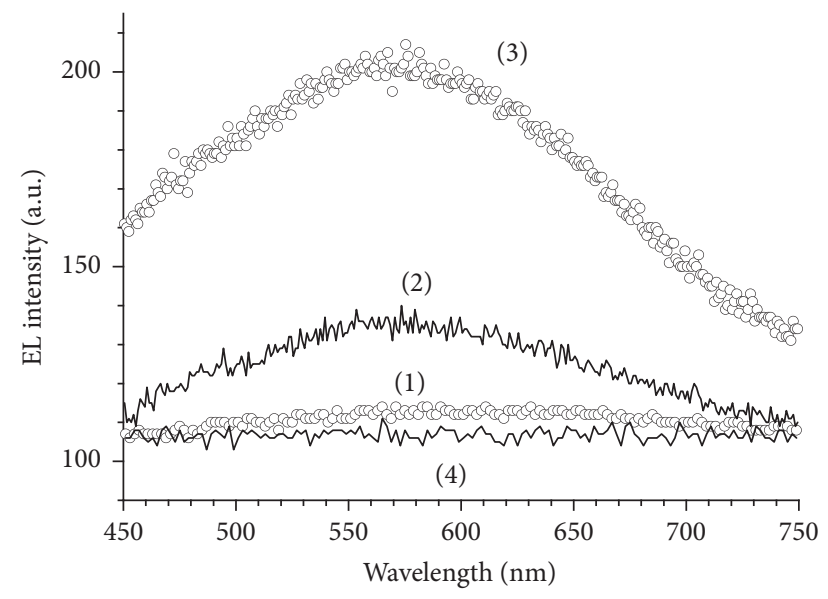

FIGURE 7: EL spectra of breakdowns measured at reverse bias of $5 \mathrm{~V}$ (1), $6 \mathrm{~V}$ (2), and $9 \mathrm{~V}$ (3). The spectrum of breakdown free region measure at $9 \mathrm{~V}$ is also shown (4).

E. P. Magomedbekov and A. B. Danilin was carried out with funding from the Ministry of Education and Science of the Russian Federation in the framework of Grant no. 14.577.21.0008 from 05.06.2015 (identification number of the project: RFMEF157714X0008).

\section{References}

[1] M. Langenkamp and O. Breitenstein, "Classification of shunting mechanisms in crystalline silicon solar cells," Solar Energy Materials and Solar Cells, vol. 72, no. 1-4, pp. 433-440, 2002.

[2] O. Breitenstein, J. P. Rakotoniaina, M. H. Al Rifai, and M. Werner, "Shunt types in crystalline silicon solar cells," Progress in Photovoltaics: Research and Applications, vol. 12, no. 7, pp. 529-538, 2004

[3] S. Dongaonkar, J. D. Servaites, G. M. Ford et al., "Universality of non-Ohmic shunt leakage in thin-film solar cells," Journal of Applied Physics, vol. 108, no. 12, Article ID 124509, 2010.

[4] S. Großer, D. Lausch, M. Werner et al., "Shunt analysis in solar cells-electro-optical classification and high resolution defect diagnostics," Energy Procedia, vol. 27, pp. 7-12, 2012.

[5] E. Sugimura, S. Takamoto, S. Tsujii, K. Hirata, A. Tani, and T. Fuyuki, "Spatially resolved electroluminescence imaging of shunt sources in crystalline silicon solar cells," Japanese Journal of Applied Physics, vol. 51, no. 10, Article ID 10NA02, 2012.

[6] O. Breitenstein, J. Bauer, K. Bothe et al., "Understanding junction breakdown in multicrystalline solar cells," Journal of Applied Physics, vol. 109, no. 7, Article ID 071101, 2011.

[7] D. Lausch, K. Petter, R. Bakowskie et al., "Identification of pre-breakdown mechanism of silicon solar cells at low reverse voltages," Applied Physics Letters, vol. 97, no. 7, Article ID 073506, 2010.

[8] D. Lausch, K. Petter, H. Von Wenckstern, and M. Grundmann, "Correlation of pre-breakdown sites and bulk defects in multicrystalline silicon solar cells," Physica Status Solidi-Rapid Research Letters, vol. 3, no. 2-3, pp. 70-72, 2009.

[9] M. Schneemann, T. Kirchartz, R. Carius, and U. Rau, "Electric properties and carrier multiplication in breakdown sites in multi-crystalline silicon solar cells," Journal of Applied Physics, vol. 117, no. 20, Article ID 205703, 2015.
[10] K. Bothe, K. Ramspeck, D. Hinken et al., "Luminescence emission from forward- and reverse-biased multicrystalline silicon solar cells," Journal of Applied Physics, vol. 106, no. 10, Article ID 104510, 2009.

[11] D. Lausch, K. Petter, B. Henke, R. Bakowskie, S. Schweizer, and C. Hagendorf, "Classification of recombination active defect structures in multicrystalline silicon solar cells," Energy Procedia, vol. 8, pp. 28-34, 2011.

[12] O. V. Feklisova, X. Yu, D. Yang, and E. B. Yakimov, "Effect of metal contamination on recombination properties of extended defects in multicrystalline Si," Physica Status Solidi C, vol. 9, no. 10-11, pp. 1942-1946, 2012.

[13] W. Kwapil, P. Gundel, M. C. Schubert et al., "Observation of metal precipitates at prebreakdown sites in multicrystalline silicon solar cells," Applied Physics Letters, vol. 95, no. 23, Article ID 232113, 2009.

[14] W. Kwapil, M. Kasemann, P. Gundel et al., "Diode breakdown related to recombination active defects in block-cast multicrystalline silicon solar cells," Journal of Applied Physics, vol. 106, no. 6, Article ID 063530, 2009.

[15] S. Brantov, O. Feklisova, and E. Yakimov, "Characterization of silicon ribbon by the SEM methods," Physica Status Solidi (C) Current Topics in Solid State Physics, vol. 8, no. 4, pp. 1384-1387, 2011.

[16] F. D. Heinz, M. Breitwieser, P. Gundel et al., "Microscopic origin of the aluminium assisted spiking effects in n-type silicon solar cells," Solar Energy Materials and Solar Cells, vol. 131, pp. 105109, 2014.

[17] O. Breitenstein, J. Bauer, P. P. Altermatt, and K. Ramspeck, "Influence of defects on solar cell characteristics," Solid State Phenomena, vol. 156-158, pp. 1-10, 2009.

[18] H. J. Möller, C. Funke, J. Bauer, S. Köstner, H. Straube, and O. Breitenstein, "Growth of silicon carbide filaments in multicrystalline silicon for solar cells," in Solid State Phenomena, vol. 156-158, pp. 35-40, 2010. 

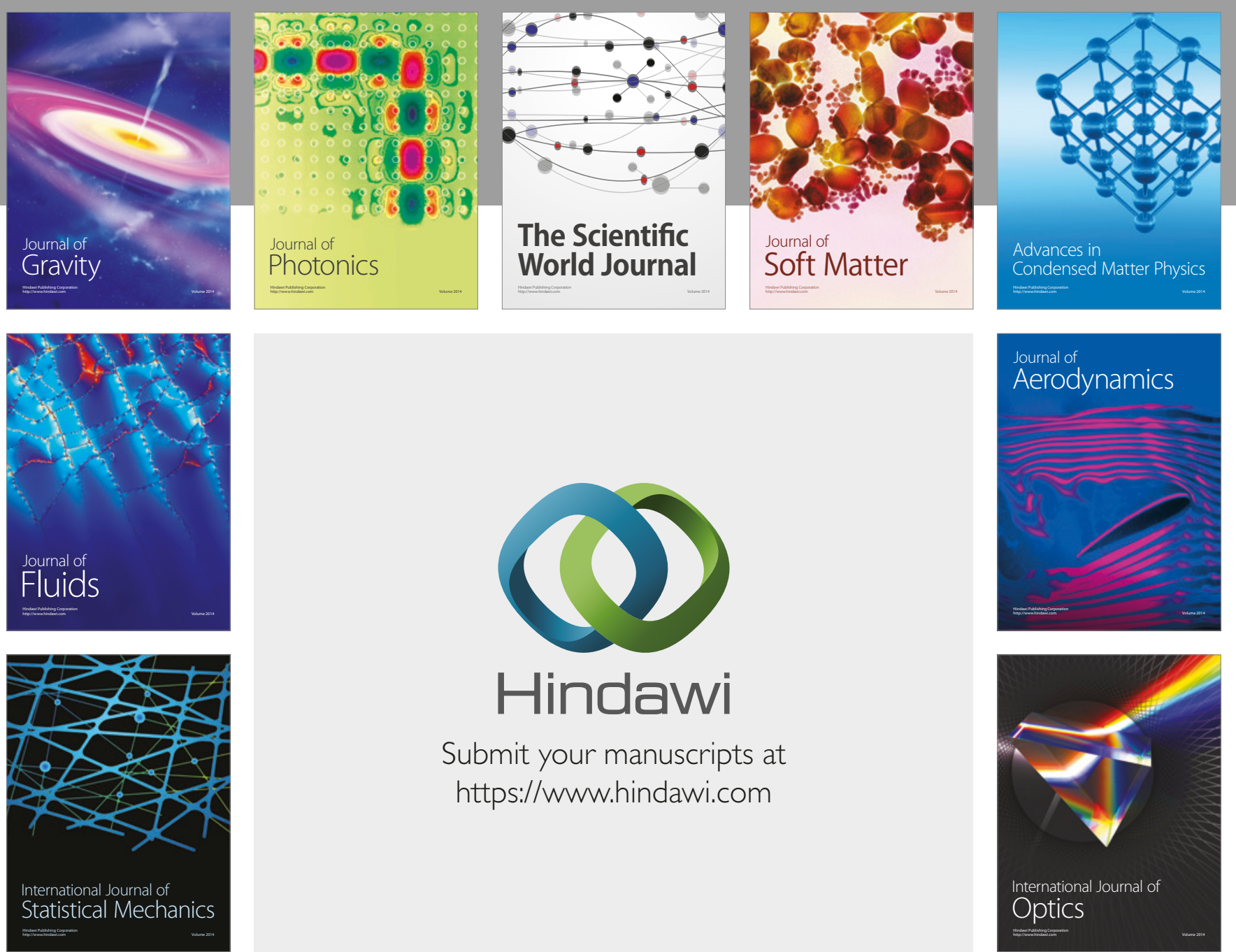

Submit your manuscripts at

https://www.hindawi.com
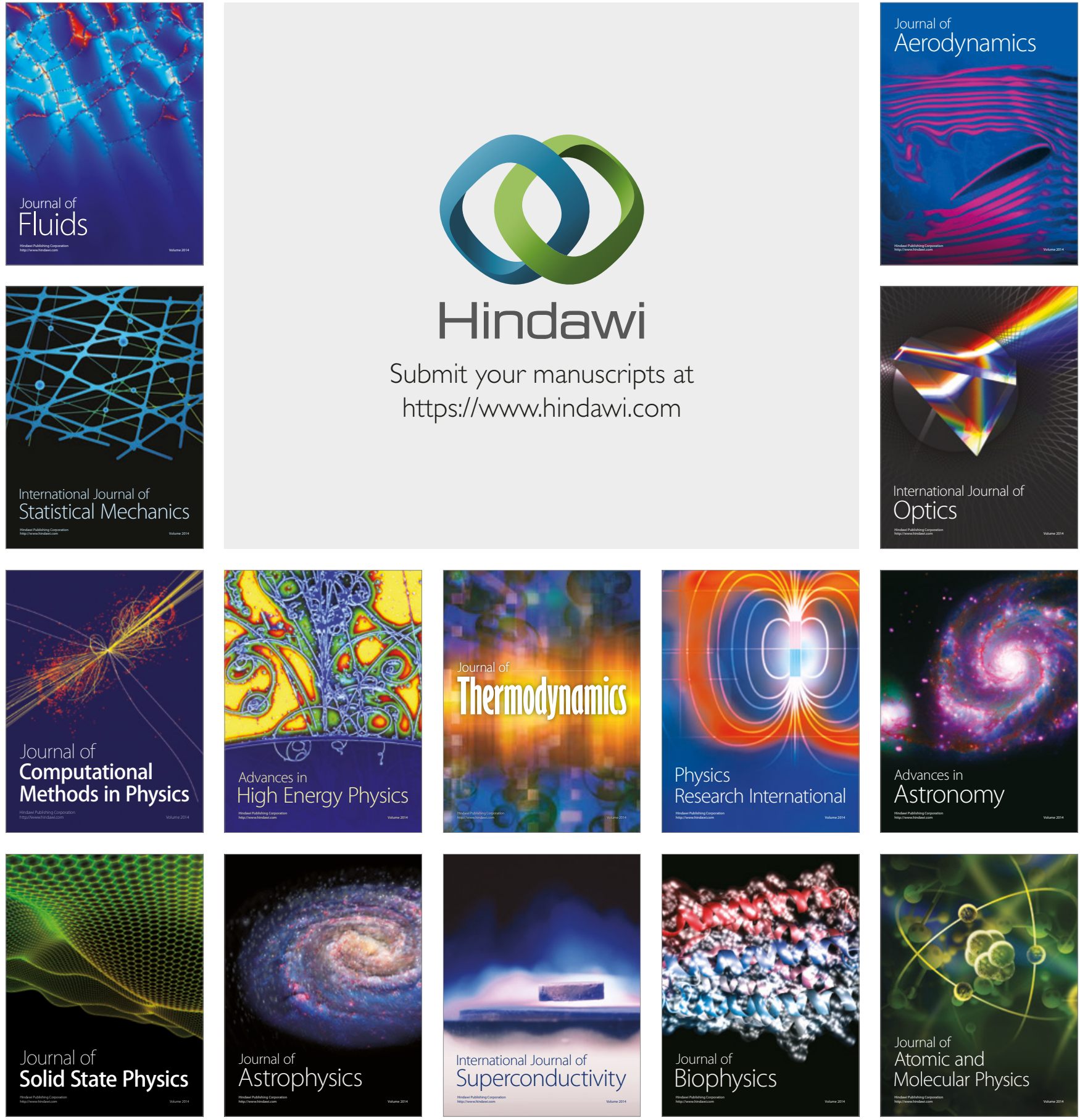